\title{
Nerve Agents and Their Detection
}

\author{
Young Jun Kim ${ }^{+}$and Jae Doo Huh
}

\begin{abstract}
Nerve agents are major chemical warfare agents with the "G series" and "V series" being the most widely known because of their lethal effect. Although not conspicuously used in major wars, the potential detrimental impact on modern society had been revealed from the sarin terror attack on Tokyo subway, which affected thousands of people. In this mini-review, major nerve agents of the "G series" and "V series" have been described along with various types of their detection methods. The physical properties and hydrolysis mechanisms of the major nerve agents are discussed since these are important factors to be considered in choosing detection methods, and specifying the procedures for sample preparations in order to enhance detection precision. Various types of extraction methods, including liquid-phase, solid-phase, gas-phase and solid-phase microextraction (SPME), are described. Recent development in the use of gas sensors for detecting nerve agents is also summarized.
\end{abstract}

Keywords: Nerve agents, Dimethyl methylphosphonate (DMMP), Chemical warfare agents (CWA), Gas sensors, Nanomaterials, Solid-phase microextraction (SPME), Carbon nanotube (CNT)

\section{INTRODUCTION}

Nerve agents are principal chemical warfare agents because of their lethal impact in battlefields. Use of chemical weapons can be traced to the ancient records of Babylon, Egypt, Greece, Rome, India, and China [1-4]. For example, hydrocyanic acid was studied in ancient Egypt for the purpose of using its fatal effect in battlefields [1]. In $1000 \mathrm{BCE}$, China produced a poisonous gas called "soul-hunting fog" containing arsenic for military uses [3]. World War I was most conspicuous among all wars in the extent of using chemical weapons in battlefields. More than 3,000 chemical species were studied for military uses during World War I by chemists including three would-be Nobel Laureates of Germany and France [5]. To curb the development and production of chemical warfare agents, a Chemical Weapons Convention (CWC) was established in 1993. Although in the current warfare regions, chemical warfare agents are not used in such large scale

Future Fusion Technology Lab., Electronics and Telecommunications research Institute (ETRI)

218 Gajeong-Ro, Useong-gu, Daejeon 305-700, Korea

${ }^{+}$Corresponding author: junkim@etri.re.kr

(Received : May. 14, 2014, Revised : Jun. 5, 2014, Accepted : Jun. 5, 2014)

This is an Open Access article distributed under the terms of the Creative Commons Attribution Non-Commercial License(http://creativecommons.org/ licenses/bync/3.0) which permits unrestricted non-commercial use, distribution, and reproduction in any medium, provided the original work is properly cited. as in World War I owing to efforts to prevent the use of chemical weapons, there have been intermittence reports of their use. Moreover use of the lethal chemical agents by terrorists increasingly endangers the everyday lives of people. In such an ostensibly safe society, where the potential danger of chemical agents is lurking, the need for devices to detect the noxious chemicals and warning people of the danger is imperative.

Detecting those chemical warfare agents usually requires large and sophisticated equipments such as gas chromatograph coupled with mass spectrometer (GC-MS), liquid chromatograph with mass spectrometer (LC-MS), and nuclear magnetic resonance (NMR) spectrometer. Although these detectors produce fairly reliable results, they are inconvenient to carry around and need special personnel to operate. Considering the urgency of the situation the chemical agents may cause, portability and easiness of operation are crucial. Much research has been endeavored to develop small and convenient sensors to detect nerve agents. In this short review, various types of nerve agents are described with emphasis on their decomposition mechanisms [6-12]. Depending on the condition of the environment the final analytes to be detected can be not only the nerve agents themselves but also their hydrolyzed products. The detecting methods, starting with the conventional methods are summarized, followed by recent studies of gas sensors for nerve agent detection. 


\section{NERVE AGENTS}

Chemical warfare agents are defined as substances "intended for use in military operations to kill, seriously injure, or incapacitate man because of its physiological effects" [13]. They are categorized into different species, nerve agents, blister agents, blood agents, choking agents and incapacitating agents. Among these, nerve agents can have the most detrimental effect on life systems. Recent reports on the Tokyo terrorist attack using sarin, the most well-known nerve agent, caused much alarm revealing its use is not limited to military purposes [14,15]. The lethal effect of nerve agents on human can be understood by the rapid spread of the chemicals upon contact with the chemicals resulting high toxicity.

The chemical structures of the nerve agents are depicted in Fig. 1. Two major categories of the nerve agents are the "G series" and the "V series". The "G series" derives its name from Germany, where these agents were synthesized. The "G series" is further divided into four different types: tabun (GA), sarin (GB), soman (GD) and cyclosarin (GF). The name $\mathrm{V}$ originates from the word venomous. "V series" agents are classified into four categories: VE, VM, VG, and VX, with VX being the most well-known. The basic chemical structure of the nerve agents is alkylphosphonic acid ester. The "G series" agents are characterized with P-F and P$\mathrm{CN}$ covalent bonds, while the "V series" have P-S linkages.

Physical properties of the nerve agents are important factors for the extent of their toxicity. Since inhalation is one of the major routes for the agents to enter into biological systems, a more volatile agent would be more lethal. Chemical agents that can be dissolved readily in organic solvents may be toxic even when they are in contact with skin. If the density of a nerve agent is high, the agent can stay near the ground surface rather than in the air above. The physical properties of the major nerve agents are described in Table $1[16,17]$. The volatilities of most nerve agents are low; therefore, they exist as liquid at room temperature rather than as gas. Thus referring to nerve agents as nerve gas is misleading. The outbreak of the sarin attack at the Tokyo subway in 1995 led to the death of 13 people and injury of $6,300[13,14]$ individuals. Considering the high toxicity of sarin the number of people dead was small. The situation can be understood by the way the chemical was installed. The sarin was place in a plastic box with a hole for evaporation, which due to low volatility must not have spread to wide range.

The degradation mechanisms of the nerve agents are crucial to both detection and decontamination [6-12]. Many studies have been

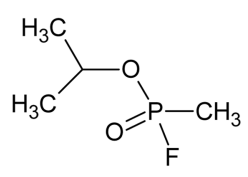

1-a. (sarin, GB)

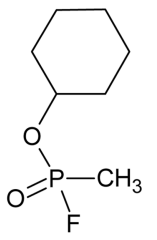

1-c. (cyclosarin, GF)<smiles>CCOP(C)(=O)SCCN(C(C)C)C(C)C</smiles>

1-e. $(V X)$ 1-b. (soman, GD)<smiles>CCOP(=O)(C#N)N(C)C</smiles>

1-d. (Tabun, GA)

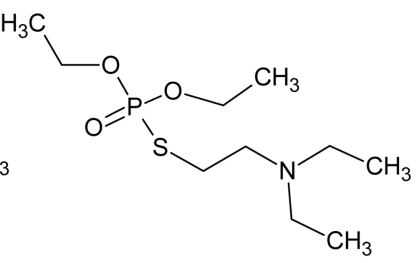

1-f. (VG)

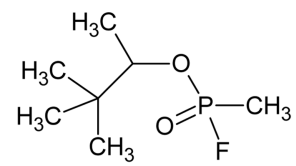

1-a. Isopropyl methylphosphonofluoridate, Sarin (GB)

1-b. Pinacolyl methylphosphonofluoridate, Soman (GD)

1-c. Cyclohexyl methylphosphonofluoridate, Cyclosarin (GF)

1-d. Ethyl N, N'-dimethylphosphoroamidocyanidate, Tabun (GA)

1-e. O-ethyl, S-2-diisopropylaminoethyl methylphosphonot -hiolate (VX)

1-f. O,O-diethyl S-[2-]diethylamino) ethylophosphorothiola -te, Aminton (VG)

Fig. 1. Chemical structures of the nerve agents.

reported regarding the decomposition of the nerve agents in the environment. It is noteworthy that most of the decomposition products of the "G series" and "V series" contain methylphosphonic acid (1-b) or phosphonic acid (5). Most nerve agents degrade through hydrolysis or oxidation. In the case of "G series" the degradation proceeds through breakage of P-F and $\mathrm{P}-\mathrm{CN}$. In the case of sarin (GB) hydrolysis occurs at P-F bond to produce isopropyl methylphosphonic acide (1-a), which can further hydrolyze into methylphosphonic acid (1-b) [10,11]. The hydrolysis of soman (GD) proceeds in a similar way as sarin (GB) does.

The similarity in the decomposition mechanism of sarin and soman can be understood from the similarity in their chemical structures. The decomposition occurs through the breakage of the P-F bond, which produces HF and alkyl methylphosphonic acid, in which the alkyl group is pinacolyl for soman and isopropyl for sarin. The final product of the decomposition of soman is methyl phosphonic acid (1-b in Fig. 2). 
The decomposition of the nerve agent GA involves two different paths depending on the mechanism of the hydrolysis since GA retains two potential reaction sites, P-O bond and P-CN (Fig. 4) $[9,11]$. Under acidic conditions, the hydrolysis proceeds through the P-O bond producing ethylphosphoryl cyanidate (4-a) and dimethylamine (4-b). When GA undergoes hydrolysis in the presence of a base catalyst, the P-CN bond disintegrates resulting in O-ethyl N, N-dimethylamino phosphoric acid (4-c) and hydrogen cyanide (4-d). Further hydrolysis of 4-c produces dimethylphosphoramidate (4-e), which in turn hydrolyzes into phosphoric acid (5).

It is noteworthy that the difference in chemical structure between "G series" and "V series" is reflected in the differences in physical properties of these chemicals. The environmental decomposition rate of VX is relatively slow compared with that of the "G series". As can be seen from Fig. 5, the hydrolysis of VX proceeds via two different paths depending on the condition. It was reported that the hydrolysis of VX proceeds faster in the high $\mathrm{pH}$ range [18]. When the $\mathrm{pH}$ is higher than 10 or lower than 6 , hydrolysis of VX occurs by breakage of the P-S bond, which in

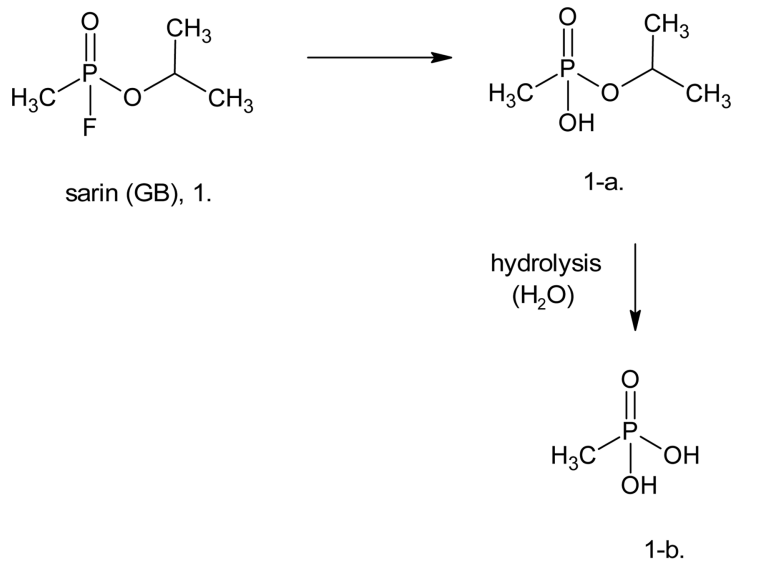

1-a. Isopropyl methylphosphonic acid 1-b. Methylphosphonic acid

Fig. 2. Hydrolysis mechanism of sarin $(\mathrm{GB}, 1$. turn produces diisopropyl ethylmercaptoamine (5-a) and ethyl methylphosphonic acid (5-b). The alkylphosphonic acid hydrolyzes into methylphosphonic acid (1-b) and ethanol (5-d).<smiles>CC(OP(C)(=O)F)C(C)(C)C</smiles>

soman GD (2)<smiles>CC(OP(C)(=O)O)C(C)(C)C</smiles>

2-a.

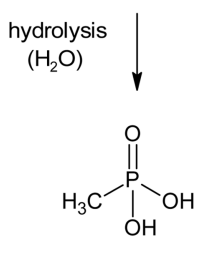

$1-\mathrm{b}$

Fig. 3. Hydrolysis mechanism of soman (GD).<smiles>CCOP(=O)(C#N)N(C)O</smiles>

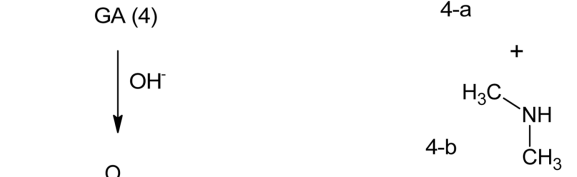<smiles>CCOP(=O)(O)N(C)C</smiles><smiles>COP(=O)(O)N(C)C</smiles>

phosphonic acid (5)

Fig. 4. Hydrolysis mechanism of GA.

Table 1. Physical properties of the nerve agents

\begin{tabular}{lccccc}
\hline \hline \multicolumn{1}{c}{ Physical properties } & Tabun $(\mathrm{GA})$ & Sarin $(\mathrm{GB})$ & Soman $(\mathrm{GD})$ & GF & VX \\
\hline boiling point $\left({ }^{\circ} \mathrm{C}\right)$ & 230 & 158 & 198 & - & 298 \\
vapor pressure $(\mathrm{mm} \mathrm{Hg})$ & $0.037\left(20^{\circ} \mathrm{C}\right)$ & $2.1\left(20^{\circ} \mathrm{C}\right)$ & $0.4\left(25^{\circ} \mathrm{C}\right)$ & $0.40\left(20^{\circ} \mathrm{C}\right)$ & $0.007\left(20^{\circ} \mathrm{C}\right)$ \\
density $(\mathrm{g} / \mathrm{mL})$ & $1.08\left(25^{\circ} \mathrm{C}\right)$ & $1.10\left(20^{\circ} \mathrm{C}\right)$ & $1.02\left(25^{\circ} \mathrm{C}\right)$ & - & $1.008\left(25^{\circ} \mathrm{C}\right)$ \\
volatility $\left(\mathrm{mg} / \mathrm{m}^{3}\right)$ & $610\left(25^{\circ} \mathrm{C}\right)$ & $22,000\left(25^{\circ} \mathrm{C}\right)$ & $3,900\left(25^{\circ} \mathrm{C}\right)$ & $59 \mathrm{ppm}$ & $10.5\left(25^{\circ} \mathrm{C}\right)$ \\
color (liquid) & colorless to brown & colorless & colorless & colorless & colorless to straw-color \\
odor & fairly fruity & odorless & fruity, oil of camphor & odorless & odorless \\
solubility $(\mathrm{g})$ (in $100 \mathrm{~g}$ water) & $9.8\left(25^{\circ} \mathrm{C}\right)$ & miscible & $2.1\left(20^{\circ} \mathrm{C}\right)$ & $3.7\left(25^{\circ} \mathrm{C}\right)$ & miscible $\left(<9.4^{\circ} \mathrm{C}\right)$ \\
\hline
\end{tabular}




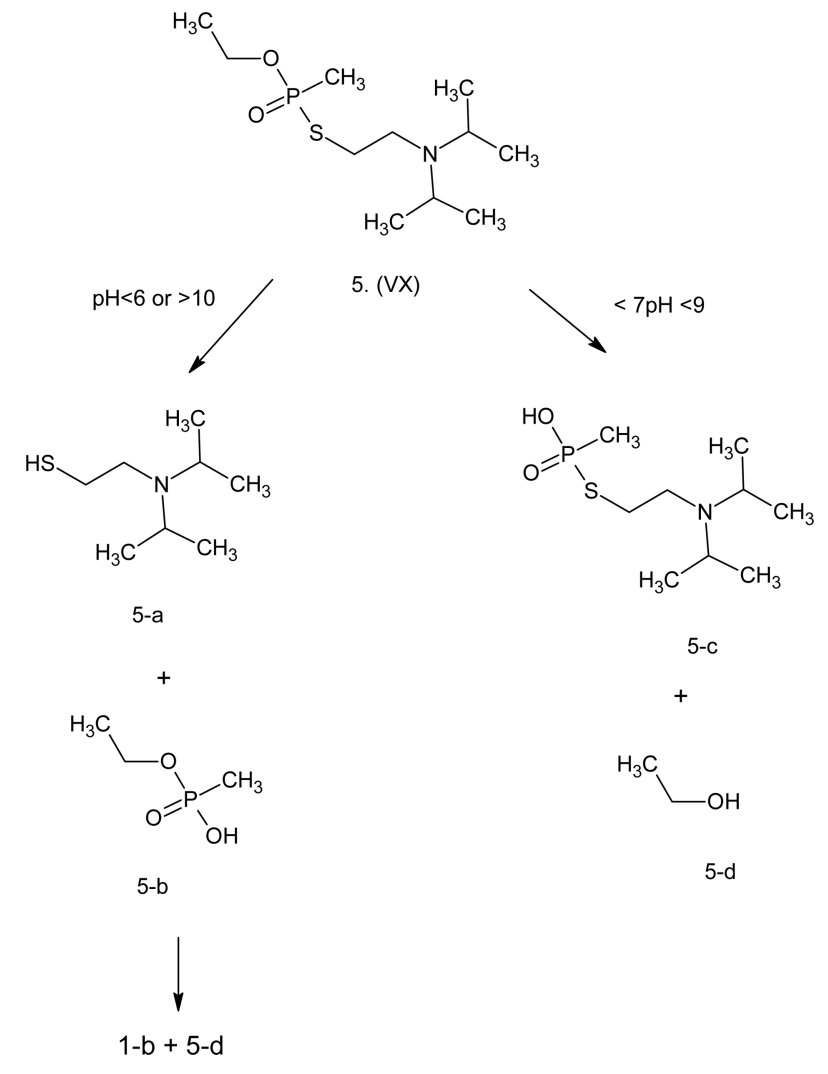

Fig. 5. Hydrolysis mechanism of VX.

When the $\mathrm{pH}$ is in the range from 6 to 10 , hydrolysis proceeds through the breakage of the P-O bond producing S(diisopropylaminoethyl methylphosphonothioic acid (5-c) and ethanol.

\section{DETECTION OF NERVE AGENTS}

\subsection{Extraction Methods}

In the environment, as described above, the chemical nerve agents undergo decomposition through hydrolysis producing alkylphosphonic acids. Since these phosphonic acids are not usually present in the environment, detection of these phosphonic acids is a reasonable method to verify the existence of nerve agents in the related matrices. Therefore, not only the original nerve agents but also their hydrolyzed products are the important source of information for discerning hazardousness [19]. Since the target analyte of the nerve agents can exist in various forms, procedures for sample handling should be carefully chosen. Usually, the analysis is time-consuming and labor-intensive. Therefore, speed is one of most important factors in sample preparation. In addition only very small quantities of toxic chemicals exist in the samples, an efficient extracting procedure is very important. Indeed, the Organization for the Prohibition of Chemical Weapons (OPCW) has provided a few reviews regarding this [20,21]. After extraction, the extracts can be analyzed by various methods [22-27]. Extraction methods can be classified according to the extraction phases used: solid-phase, liquid-phase and gas-phase methods.

Solid-phase extraction (SPE) is the most widely used method since its procedure is simple compared with other extraction methods. Samples are transported through a column packed with solid sorbent materials. As the samples pass through the column, analytes are adsorbed onto sorbent. When proper solvents are eluted through the column, the adsorbed material is extracted to be eluted. It is important to use minimum amount of solvent especially for samples with a trace amount of chemical agents. Various types of packing materials are used in order to provide special functions for the extraction process, such as polymers, carbon nanotubes, and cation- and anion-exchange materials [28-35].

Solid-phase microextraction (SPME) is a method used increasingly due to its advantages in sample preparation. The merits for sample preparation make it an efficient method for onsite analysis. The target sample is exposed to the extraction material which is dispersed on a substrate. The extraction phase that contains the target analytes can be directly connected to a GC or extracted with proper solvents [36-39].

The syringe is one of the important parts in SPME [40]. The needle tip of the syringe is made of a fused silica fiber and metal part is coated with sorption materials. Various types of SPME fibers are commercially available from Supelco (Bellefonte, Pam USA) [41,42]. Since the function of the fiber is to absorb the analytes, choosing the SPME coating affects the analysis result. For example the Supelco products are categorized into non-polar, bi-polar and polar coating materials with varying thickness from 7 to $100 \mu \mathrm{m}$. Polydimethylsiloxane (PDMS) is a non-polar coating for extracting nonpolar samples, while polyacrylate (PA) is used for application for extracting polar analytes. PDMS/ divinylbenzene (DVB) is a bipolar coating material and can be used to analyze aromatic hydrocarbons and volatile organic solvent (VOC) hydrocarbons.

The "G series" nerve agents, sarin, soman and tabun were analyzed by SPME method using GC as a detector. The samples were drawn from various types of waters by taking the water samples from river, sea and sewage. The limit of detection (LOD) was turned out to be $0.05 \mu \mathrm{g} / \mathrm{L}$. Also VX in those waters was analyzed by SPME under the same analysis condition resulting 
LOD of $0.5 \mu \mathrm{g} / \mathrm{L}$. For these analyses PDMS/DVB of $65 \mu \mathrm{m}$ was used as the fiber coating material [39]. In another analysis DMMP, which is used as a simulant for sarin, was analyzed using FID as a detector with LOD of $1.11 \mu \mathrm{g} / \mathrm{L}$. In this case somewhat more polar fiber material was used, the copolymer of hydroxylterminated silicone oil and DVB [43]. Clothing contaminated with VX was analyzed using MS as a detector and PDMS the fiber coating material [44].

Solvent extraction is the most typical method used in conventional analysis, where immiscible solvents are used for extraction. In order to extract organophosphorus nerve agents and simulants from painted wallboard, mixture of dichloromethane (DCM) and acetone (1:1) was used [45]. Soils contaminated with Vseries agent was extracted with mixture of DCM and hexane. The analysis was accomplished with high sensitivity based on gas chromatography (GC) with flame photometric detection (FPD) [46].

Gas phase analysis mostly accompanies with pre-concentration. When gas phase method is used, the media is mostly air environment in which the concentration of the analyte is so small as to require pre-concentration procedure before being analyzed by GC. Normally when thermal desorption (TD) tube is used for pre-concentration, GC is used as analysis equipment $[47,48]$. Instead of polymer sorbent material, glass beads with some porosity was used to analyze VX nerve agent that exists in air environment with very low concentration [49]. Since different from polymer absorbent the porous glass bead does not dissolve in solvents the extraction can be processed using solvent. In this report isopropyl alcohol was used as the solvent to be analyzed by LC-MS.

\subsection{Gas Sensors}

Usually gas sensors are smaller and easier to carry around than the apparatus for chromatographic analysis. Moreover, sample handling is simple and the analysis takes much less time, which can be crucial in detecting toxic chemicals [50].

Carbon nanotube networks were used as a sensing material for detecting DMMP at room temperature with LOD of $1 \mathrm{ppm}$ [51]. Linearity was obtained in the range from 1 to $40 \mathrm{ppm}$. The carbon nanotube film was formed on a flexible substrate of polyimide (PI). In order to facilitate the contact between the substrate and the CNT, the substrate was pretreated with poly (dimethyldiallyammoniumchloride) (PDDA) to provide cationic charge while CNT was treated with $\mathrm{O}_{2}$ plasma to retain negative charge. It is noteworthy that when bent in a glass tube of $5 \mathrm{~mm}$ radius, the sensor substrate showed only $5.6 \%$ variation in response, showing reasonable flexibility.
The same group prepared CNT sensor on a silicon wafer [52].

The variability of electrical property of a conducting polymer due to absorption of nerve agent was used as sensing element. Moreover the surface of the sensing material was increased by forming the polypyrrole hybrid nanoparticles on the surface of iron oxyhydroxide nanoparticle [53]. Dimethyl methylphosphonate (DMMP), which is a simulant molecule for the toxic sarin gas, was able to be detected to $0.1 \mathrm{ppb}$. Such a high level of detection capability can be traced to the high surface area due to characteristic hybrid nanostructure.

Switchability of electrical properties in polymer-dispersed liquid crystal (PDLC) was used for detecting DMMP [54]. Carbon nanotube (CNT) was also mixed with the PDLC in forming sensing materials. The composite sensor exhibited linearity in the concentration range of 5 to $250 \mathrm{ppm}$ with the response time of 125 seconds. PDLC can be normally prepared by polymerizing monomers with light ranging from visible to ultraviolet, producing polymers with phase-separated domains. The unique electro-optic properties of PDLC are utilized in various applications in electrooptics [55-60].

The use of CNTs in the composite improves the physical properties and the alignment of LC affects ordering of CNTs [61]. Since CNTs are conductive, the PDLC composite of CNTs retains certain amount of conductivity, which can vary as the alignment of the nematic phase changes. When DMMP interacts with the sensor material, the variation in alignment of the CNT-doped PDLC is reflected in the change of conductivity of the PDLC.

\section{CONCLUSION}

Although originally developed for military use, chemical nerve agents are currently endangering the society. The terror attack on the Tokyo subway using sarin alarmed the modern civil society of the use of the nerve agnets beyond military purposes. Conventionally detecting the chemical toxins requires sophisticated chromatographic methods, GC-MS and LC-MS. Moreover, different natures of matrices, contaminated with nerve agents, further complicate detection process including sample pretreatment and pre-concentration. However the need for fast analysis of nerve agents instigated developing simple yet precise methods. The conventional gas sensors are thought to be the potential candidates for the purpose. Indeed, recent development in nanomaterials contributed much to the novel sensor materials and many different types of nanomaterials are being studied for application as nerve agent detectors. Although the trend has been 
very recent and not much widespread yet, nanomaterials for sensing purposes are expected to find many applications in detecting nerve agents in the near future.

\section{REFERENCES}

[1] Osius TG. "The historic art of poisoning", Med Bull (Ann Arbor), Vol. 23, pp. 111-116, 1957.

[2] A. Mayor, Greek Fire, Poison Arrows, and Scorpion Bombs: Biological and Chemical Warfare in the Ancient World Woodstock, NY: Overlook Press; 2003.

[3] Smart JK. History of Chemical and Biological Warfare Fact Sheets. Aberdeen Proving Ground, Md: US Army Chemical and Biological Defense Command; 1996. Special Study 50.

[4] A. Mayor, Greek Fire, Poison Arrows, and Scorpion Bombs: Biological and Chemical Warfare in the Ancient World.Woodstock, NY: Overlook Press; 2003.

[5] Haber LF. The Poisonous Cloud: Chemical Warfare in the First World War. Oxford, England: Clarendon Press; pp. 1540, 1986.

[6] M. J. Small, "Compounds formed from the chemical decontamination of $\mathrm{HD}, \mathrm{GB}$, and $\mathrm{VX}$ and their environmental fate", Technical report 8304, US Army medical bioengineering research and development laboratoty, Fort Detrick, Frederick, MD; AD A149515, 1984

[7] R. Trapp, "The detoxification and natural degradation of chemical warfare agents", Stockholm, Sweden: International Peace Institute (SIPRI), 1985.

[8] D. N. Clark, "Review of reaction of chemical agents in water", Battelle, Columbus, OH. AD-A213 287. Defense Technical Information Center, Ft. Belvoir, VA, 1989.

[9] M. L. Sanches, C. R. Russell, and C. L. Randolf, "Chemical weapons convention (CWC): signature analysis", DNATR-92-73, Defense Nuclear Agency, Alexandria, VA, 1993.

[10] A. F. Kingery and H. E. Allen, "The environmental fate of organophosphorus nerve agents: A review", Toxicol Environ. Chem., Vol. 47, pp. 155-184, 1994.

[11] M. G. MacMaughton and J. H. Brewer, "Environmental chemistry and fate of chemical warfare agents", Final Report, SwRI Project 015864, Southwest Research Institute, San Antonio, TX, 1994.

[12] N. B. Munro, S. S. Talmage, G. D. Griffin, L. C. Waters, A. P. King, and V. Hauschil, "The sources, fate, and toxicity of chemical warfare agent degradation products, Environ. Health Perspect., Vol. 107, pp. 933, 1999.

[13] H. Morita, N. Yanagisawa, and T. Nakajima, "Sarin poisoning in Matsumoto, Japan", Lancet, Vol. 346, No. 8970, pp. 290-293, 1995.

[14] Department of the Army. NATO Handbook on the Medical Aspects of NBC Defensive Operations. AMedP-6, Part 3. Washington, DC: DA; Field Manual 8-9, 1996.

[15] T. Okumura, N. Takasu, and S. Ishimatu, "Report on 640 victims of the Tokyo subway sarin attack", Ann. Emerg. Med., Vol. 28, No. 2, pp. 129-135, 1996.

[16] Sidell FR. Nerve agents. In: Sidell FR, Takafuji TE, Franz D. R., eds. Textbook of Military Medicine: Medical Aspects of Chemical and Biological Warfare. Falls Church, VA: Officeof the Surgeon General, U.S. Army; pp. 129-179, 1997.

[17] Ellison D. H. Handbook of Chemical and Biological Warfare Agents. Boca Raton, FL: CRC Press; pp. 220-239, 2000.

[18] J. Epstein, J. J. Callahan, and V. E. Bauer, "The kinetics and mechanisms of hydrolysis of phosphonothiolates in dilute aqueous solution", Phosphorus, Vol. 4, pp. 157-163, 1974.

[19] H. S. N. Lee, M. T. Sng, C. Basheer, and H. K. Lee, "Determination of basic degradation products of chemical warfare agents in water using hollow fibre-protected liquid-phase microextraction with in-situ derivatisation followed by gas chromatography-mass spectrometry", J. Chromatogr. A, Vol. 1196-1197, No. 1-2, pp. 125-132, 2008.

[20] M. L. Kuitunen, in: M. Mesilaakso (Ed.), Chemical Weapons Convention Chemical Analysis: Sample Collection, Preparation and Analytical Methods, Wiley, Chichester, UK, 2004, p. 163.

[21] J. Hendrikse, in: M. Mesilaakso (Ed.), Chemical Weapons Convention Chemical Analysis: Sample Collection, Preparation and Analytical Methods, Wiley, Chichester, UK, 2004 , p. 89.

[22] Organization for the Prohibition of Chemical Weapons (OPCW), $1997<\mathrm{http}: / /$ www.opcw.org>.

[23] I. G. Zenkevich, Experimentally Measured Retention Indices, 2005.

[24] E. J. Staples, Creating a Compound Library for Chemical Warfare Agents for the Znose, 2006.

[25] Y. C. Yang, J. A. Baker, and J. R. Ward, "Decontamination of chemical warfare agetns", Chem. Rev. Vol. 92, pp. 17291743, 1992.

[26] P. Edwadrs, R. L. Maynard, in: T. C. Marrs, R. L. Maynard, F. R. Sidel (Eds.), Chemical Warfare Agents Toxicology and Treatment, Wiley and Sons, Chichester, England, p. 684, 2007.

[27] F. J. Vocci, T. A. Yevich, and C. L. Punte, "Inhalation toxicity studies with aerosols of sesqui-mustard", Toxicol. Appl. Pharmacol. Vol. 5, pp. 677-684, 1963.

[28] C. L. Arthur and J. Pawliszyn, "Solid phase microextraction with thermal desorption using fused silica optical fibers", Anal. Chem. Vol. 62, p. 2145-2148, 1990.

[29] J. Pawliszyn, Solid Phase Microextraction, Theory and Practice, Wiley-VCH, 1997.

[30] L. Pillonel, J. O. Bossett, and R. Tabacchi, "Rapid preconcentration and enrichment techniques for the analysis of food volatile. A review", Lebensm. Wiss. U. Technol. Vol. 35, pp. 1-14, 2002.

[31] W. Wardencki, M. Michulec, and J. A. Curylo, "A review of theoretical and practical aspects of solid-phase microextraction in food analysis", Int. J. Food Sci. Technol., Vol. 39 , pp. 703, 2004.

[32] F. Pragst, "Application of solid-phase microextraction in analytical toxicology", Anal. Bioanal. Chem., Vol. 388, pp. 1393-1414, 2007.

[33] G. Ouyang and J. Pawliszyn, "SPME in environmental analysis", Anal. Bioanal. Chem., Vol. 386, p. 1059-1073, 2006.

[34] J. S. Aulakh, A. K. Malik, V. Kaur, and P. Schmitt-Kopplin, 
"A review on solid phase micro extraction-high performance liquid chromatography (SPME-HPLC) analysis of pesticides", Anal. Chem., Vol. 35, pp. 71-85, 2005.

[35] C. Bicchi, C. Cordero, E. Liberto, B. Sgorbini, and P. Rubiolo, "Headspace sampling of the volatile fraction of vegetable matrices", J. Chromatogr. A, Vol. 1184, pp. 220-233, 2008.

[36] A. M. Kanamori-Kataoka and Y. Seto, "Laboratory identification of the nerve gas hydrolysis products alkyl methylphosphonic acids and methylphosphonic aicd by gas chromatography-mass spectrometry after tert-butyldimethylsilylation", J. Health Sci., Vol. 54, pp. 513-523, 2008.

[37] A. F. Kingery and H.E. Allen, "The environmental fate of organophosphorus agents: a review", Toxicol Environ. Chem., Vol. 47, pp. 155, 1994.

[38] R. L. Gustafson and A. E. Martell, "A kinetic study of the copper(II) chelate-catalyzed hydrolysis of isopropyl methylphosphonofluoridate (Sarin)", J. Am. Chem. Soc., Vol. 84, pp. 2309-2316, 1962.

[39] H. A. Lakso and W. F. Ng, "Determination of chemical warfare agents in natural water samples by solid phase microextraction”, Anal. Chem., Vol. 69, pp. 1866-1872, 1997.

[40] J. Pawliszyn, Applications of Solid Phase Microextraction, Royal Society of Analytical Chemistry, Cambridge, 1999.

[41] T. P. Gbatu, K. L. Sutton and J. A. Caruso R. "Development of new SPME fibers by sol-gel technology for SPMEHPLC determination of organometals", Anal. Chim. Acta, Vol. 402, pp. 67-79, 1999.

[42] H. Prosen and L. Zupancic-Kralj, "Solid-phase microextraction", Trends Anal. Chem., Vol. 18, pp. 272-282, 1999.

[43] M. M. Liu, Z. R. Zeng, C. L. Wang, Y. J. Tan, and H. Liu, "Solid-phase microextraction of phosphate and methylphosphonate using novel fibers coated with a sol-gel-derived silicone-divinylbenzene copolymer", Chromatographia, Vol. 58, pp. 597, 2003.

[44] G. L. Hook, G. Kimm, G. Betsinger, P. B. Savage, A. Swift, T. Logan, and P. A. Smith, "Solid phase microextraction sampling and gas chromatographic system for field applications", J. Sep. Sci., Vol. 26, pp. 1091-1096, 2003.

[45] J. H. Wahl and H. A. Colburn, "Extraction of chemical impurities for forensic investigations: a case study for indoor release of a sarin surrogate", Build. Environ. Vol. 45, pp. 1339-1345, 2010.

[46] C. Montauban, A. Be'gos, and B. Bellier, "Extraction of nerve agent VX from soil", Anal. Chem.,Vol. 76, p. 2791, 2004.

[47] P. A. Smith, C. R. J. Lepage, D. Koch, H. D. M. Wyatt, G. L. Hook, G. Betsinger, R. P. Erickson, and B. A. Eckenrode, "Detection of gas-phase chemical warfare agents using field-portable gas chromatography-mass spectrometry system: instrument and sampling strategy considerations", Trends Anal. Chem., Vol. 23, pp. 296-306, 2004.

[48] P. A. Smith, C. J. Lepage, M. Lukacs, N. Martin, A. Shufutinsky, and P. B. Savage, "Field-portable gas chromatography with transmission quadrupole and cylindrical ion trap mass spectrometric detection: chromatographic retention index data and ion/molecule interactions for chemical warfare agent identification", Int. J. Mass Spectrom., Vol. 295, p. 113, 2010.

[49] P. A. Smith, M. T. Sng, B. A. Eckenrode, S. Y. Leow, D. Koch, R. P. Erickson, C. R. J. Lepage, and G. L. Hook, "Towards smaller and faster gas chromatography-mass spectrometry systems for field chemical detection", J. Chromatogr. A, Vol. 1067, pp. 285-294, 2005.

[50] Y. J. Kim, H. Y. Yu, I. B. Back, and C. A. Choi, "Use of gas-sensor array technology in lung cancer diagnosis", $J$. Senor Sci. \& Tech., Vol. 22, No. 4, pp. 249-255, 2013.

[51] Y. Wang, Z. Yang, Z. Hou, D. Xu, L. Wei, Eric S. W. Kong, and Y. Zhang, "Flexible gas sensors with assembled carbon nanotube thin films for DMMP vapor detection", Sens. Actuator B-Chem., Vol. 150, pp. 708-714, 2010.

[52] Y. Y. Wang, Z. H. Zhou, Z. Yang, X. H. Chen, D. Xu, and Y. F. Zhang, "Gas sensors based on deposited single-walled carbon nanotube networks for DMMP detection", Nanotechnology, Vol. 20, pp. 345502-1-345502-8, 2009.

[53] J. S. Lee, D. H. Shin, J. Jun, and. Jang, "Multidimentional polypyrroe/iron oxyhydroxide hybrid nanoparticles for chemical nerve gas agent sensing application", ACS Nano, Vol. 7, No. 11, pp. 10139-10147, 2013.

[54] Y. T. Lai, J. C. Kuo, and Y. J. Yang, "Polymer-dispersed liquid crystal doped with carbon nanotubes for dimethyl methylphosphonate vapor-sensing application", Appl. Phys. Lett., Vol. 102, pp. 191912-191913, 2013.

[55] D. Cupelli, F. P. Nicoletta, S. Manfredi, M. Vivacqua, P. Formoso, G. D., Filpo, and G. Chidichimo, "Self-adjusting smart windows based on polymer-dispersed liquid crystals", Sol. Energy Mater. Sol. Cells, Vol. 93, No. 11, pp. 20082012, 2009.

[56] C. D. Sheraw, L. Zhou, J. R. Huang, D. J. Gundlach, T. N. Jackson, M. G. Kane, I. G. Hill, M. S. Hammond, J. Campi, B. K. Greening, J. Francl, and J. West, "Organic thin-film transistor-driven polymer-dispersed liquid crystal displays on flexible polymer substrates", Appl. Phys. Lett., Vol. 80, No. 6, pp. 1088-1090, 2002.

[57] Y. J. Liu, X. W. Sun, H. I. Elim, and W. Ji, "Gain narrowing and random lasing from dye-doped polymer-dispersed liquid crystals with nanoscale liquid crystal droplets", Appl. Phys. Lett., Vol. 89, No. 1, p. 011111, 2006.

[58] Y. J. Liu and X. W. Sun, "Electrically switchable computergenerated hologram recorded in polymer-dispersed liquid crystals", Appl. Phys. Lett., Vol. 90, No. 19, p. 191118, 2007.

[59] H. Ren, Y. H. Lin, Y. H. Fan, and S. T. Wu, "Polarizationindependent phase modulation using a polymer-dispersed liquid crystal", Appl. Phys. Lett., Vol. 86, No. 14, p. 141110 , 2005.

[60] E. Scherschener, C. D. Perciante, E. A. Dalchiele, E. M. Frins, M. Korn, and J. A. Ferrari, "Polymer-dispersed liquid-crystal voltage sensor", Appl. Optics, Vol. 45, No. 15, p. 3482, 2006.

[61] R. Basu and G. S. Iannacchione, "Nematic anchoring on carbon nanotubes", Appl. Phys. Lett., Vol. 95, No. 17, p. 173113, 2009. 